\title{
Effects of resistant dextrin for weight loss in overweight adults: a systematic review with a meta-analysis of randomized controlled trials
}

\author{
Junichi Mukai ${ }^{1 *}$, Yuta Tsuge ${ }^{2}$, Michiko Yamada ${ }^{1}$, Katsuya Otori ${ }^{1,3}$ and Koichiro Atsuda ${ }^{2,4}$
}

\begin{abstract}
Background: Randomized controlled trials (RCTs) reported that resistant dextrin (RD) exerted pleiotropic effects on humans. However, limited information is available on the effects of RD for weight loss. We conducted a systematic review with a meta-analysis to summarize the available literature and compare the efficacy of RD for weight loss with that of a placebo in overweight adults.

Methods: We searched the electronic databases MEDLINE, EMBASE, The Cochrane Central Register of Controlled Trials (CENTRAL), CINAHL, Web of Science, ClincalTrials.gov, and Japana Centra Revuo Medicina (Ichushi-web) for studies from their onset to November 2016, and there was no language restriction. Trials were included if they were RCTs (1) comparing the effects of RD with a placebo in adults (18 years or older), (2) reporting body mass index, and (3) including overweight/obese subjects as defined by the authors of RCTs. The weighted mean difference with a 95\% confidence interval (Cl) was calculated using a random-effects model.

Results: Of the 484 studies retrieved, 3 RCTs involving 275 subjects were included in our review. The durations of RCTs ranged between 8 and 12 weeks. All RCTs were conducted in Asian countries. RD significantly improved body mass index [mean difference $-0.39(95 \% \mathrm{Cl}-0.57$ to -0.21$) \mathrm{kg} / \mathrm{m}^{2}, p<0.01$ ] and body weight [mean difference -0 . $81(95 \% \mathrm{Cl}-0.93$ to -0.69$) \mathrm{kg}, p<0.01]$ in overweight adults.

Conclusion: Our review suggests that RD exerts beneficial effects for weight loss in overweight adults. More RCTs with different populations and longer follow-ups are needed in order to confirm that supplementation with RD has beneficial effects for weight loss in overweight adults. We consider this review to provide important information for the future submission of food with health claims.
\end{abstract}

Keywords: Dietary fiber, Resistant dextrin, Overweight, Meta-analysis, Systematic review

\section{Background}

According to the World Health Organization, the prevalence of obesity has more than doubled worldwide in the past 30 years. In 2014, there were more than 1.9 billion overweight adults and 600 million obese adults [1]. The prevalence of obesity has increased in Asia, varying from $10 \%$ in India to $28.3 \%$ in Thailand. In Asia, the prevalence of diabetes is higher than that expected based on

\footnotetext{
* Correspondence: mukai11@kitasato-u.ac.jp

${ }^{1}$ Laboratory of Clinical Pharmacy Education, School of Pharmacy, Kitasato

University, 5-9-1, Shirokane, Minato-ku, Tokyo 108-8641, Japan

Full list of author information is available at the end of the article
}

the prevalence of obesity $[2,3]$. Dietary fiber has been reported to exert several beneficial effects. For example, a cross-over study reported that a high dietary fiber intake improved plasma glucose levels in patients with type 2 diabetes [4]. A cross-sectional study demonstrated that fiber intake was associated with weight loss [5]. Another clinical study showed that dietary fiber assisted with weight loss in overweight subjects [6]. Resistant dextrin (RD), a soluble dietary fiber, is an indigestible glucose polysaccharide (rich in $\alpha-1,2$ or $\alpha-1,3$ linkages) that is formed when starch is heated and treated with enzymes, and is made of wheat or maize starch. RD acts 
as a fermentation substrate in the colon $[7,8]$. It has been classified as FOSHU (foods for special health uses) in Japan or GRAS (generally recognized as safe) by the Food and Drug Administration in the United States. Several studies have reported that RD exerts pleiotropic effects. For example, a recent randomized controlled trial (RCT) including healthy subjects found that RD significantly improved serum triglyceride levels and visceral fat accumulation over those with a placebo in a 12-week follow-up [9]. Another RCT that included overweight subjects demonstrated that body mass index (BMI) was significantly lower with RD than with a placebo [10]. Although a recent meta-analysis of 37 cross-over RCTs has revealed the attenuation of postprandial blood glucose in healthy subjects administered RD [11], to the best of our knowledge, there is only systematic review of RD with a focus on glycemic control. We hypothesized that the effects of RD for weight loss may be consistent across RCTs related to this area [10]. These findings may provide a novel insight into the effects of RD. Accordingly, we conducted a systematic review with a meta-analysis to summarize the available literature and compare the effects of RD for weight loss with those of a placebo in overweight adults.

\section{Methods}

\section{Search methods for the identification of RCTs}

We searched the electronic databases MEDLINE, EMBASE, The Cochrane Central Register of Controlled Trials (CENTRAL), CINAHL, Web of Science, ClincalTrials.gov, and Japana Centra Revuo Medicina (Ichushiweb) for studies from their onset to November 2016 using the following Medical Subject Headings and text words as search terms: "dextrins", "maltodextrin", "resistant dextrin", "resistant maltodextrin", "indigestible dextrin", "indigestible maltodextrin", "nutriose", "randomized", and "randomized control trial". We used a filter to restrict our search to "Randomized Controlled Trial" when using MEDLINE. The search strategy for MEDLINE was as follows: "Dextrins"[Mesh] OR "maltodextrin" [Supplementary Concept] OR "NUTRIOSE" [Supplementary Concept]. A reference search was also implemented from relevant studies in order to identify more RCTs. There was no language restriction. Trials were included if they were RCTs (1) comparing the effects of RD with a placebo in adults (18 years or older), (2) reporting BMI, and (3) including overweight/obese subjects as defined by the authors of RCTs. We excluded RCTs involving healthy subjects. We also excluded cross-over trials. The study search was undertaken independently by two authors (MY and JM). Any discrepancies were settled by discussions between the two assessors. They also assessed RCT quality. We extracted data on the trial country, trial design, daily dose of RD, subjects (mean BMI, Hemoglobin A1c, and age at baseline), duration of the intervention, trial population, reporting of BMI, body weight, and adverse events. BMI was used as the primary endpoint. The secondary endpoint was body weight. This systematic review did not require Ethics Committee approval.

\section{Quality assessment}

Study quality was quantified by the Jadad scale, which is used to evaluate the appropriateness of the randomization technique, the method used for doublemasking, and descriptions of dropouts or withdrawals [12]. The Jadad scale ranges between zero and five. Studies that scored 3 points or higher were defined as high quality and were included in the analysis. Additionally, the risk of bias of the RCTs included was assessed based on the Cochrane handbook of systematic reviews [13]. Seven items were examined for the risk of bias: random sequence generation, allocation concealment, the blinding of participants and personnel, blinding of outcome assessments, incomplete outcome data, free of selective reporting, and baseline imbalance as other sources of bias. Each of the seven items was scored as a "low risk", "unclear risk", or "high risk".

\section{Statistical analysis}

The weighted mean difference with a 95\% confidence interval (CI) was calculated for each outcome. The heterogeneity of each outcome was evaluated using chisquared and $\mathrm{I}^{2}$ statistics. A value of $50 \%$ or more was defined to represent marked heterogeneity according to the Cochrane handbook of systematic reviews [13]. We used a random-effects model (the DerSimonian and Laird method [14]) to more conservatively assess outcomes. In the meta-analysis, multiple RD groups from a trial were combined into a single group [13]. A sensitivity analysis was performed using a fixed-effects model (the inverse variance method [13]). Additionally, subgroup analyses were performed by excluding patients with diabetes, subjects with different BMIs $\left(>25 \mathrm{~kg} / \mathrm{m}^{2}\right)$, and RCTs with the largest sample sizes. If necessary, variances for the change from baseline were calculated using a correlation efficient of 0.5 [15]. The metaanalysis was performed using review manager 5.3 software (Cochrane Collaboration, Oxford, UK). A P value less than 0.05 was considered to be significant.

\section{Results}

We identified 484 studies in the database search. Forty full text studies were retrieved after screening titles and abstracts. Five studies involving 3 RCTs were ultimately included in our review. Figure 1 shows the identification process for eligible RCTs [10, 16-19] following PRISMA [20]. Table 1 shows the characteristics of RCTs included 
Records identified through database searches

$$
(n=484)
$$

MEDLINE (302), EMBASE (33), CENTRAL (9), CINAHL (3), Web of Science (8),

ClincalTrials.gov (36), Ichushi-web (93)

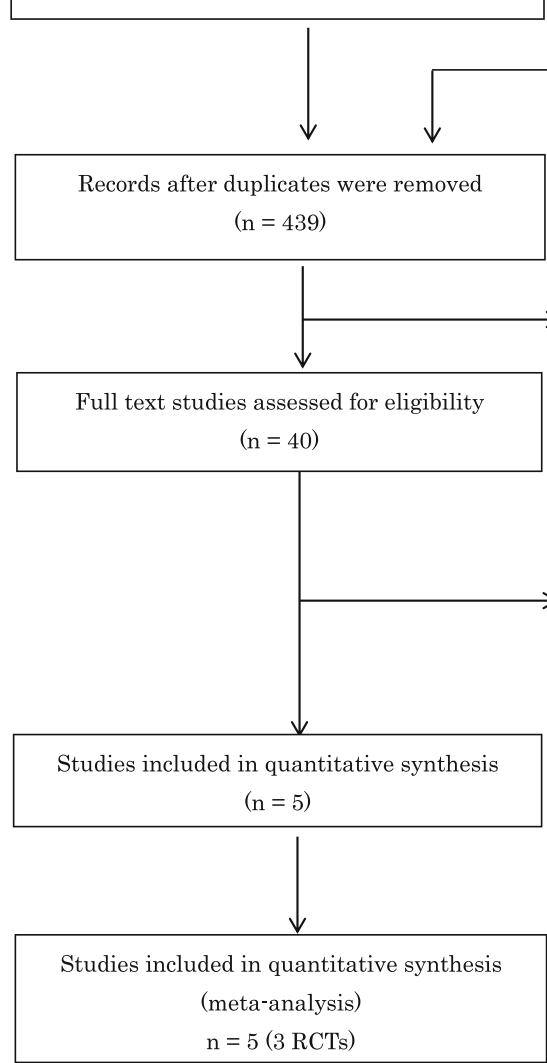

Fig. 1 Identification process for eligible randomized controlled trials (RCTs)

Table 1 Characteristics of RCTs included in the meta-analysis

\begin{tabular}{|c|c|c|c|c|c|c|c|c|c|c|c|c|}
\hline Trial (Year) & Country & Design & Intervention (N) & $\begin{array}{l}\text { Follow- } \\
\text { up (weeks) }\end{array}$ & $\begin{array}{l}\text { Co- } \\
\text { intervention }\end{array}$ & $\begin{array}{l}\text { Jadad } \\
\text { score }\end{array}$ & $\begin{array}{l}\text { Baseline } \\
\text { BMl } \\
\left(\mathrm{kg} / \mathrm{m}^{2}\right)\end{array}$ & $\begin{array}{l}\text { Baseline } \\
\text { HbA1c } \\
(\%)\end{array}$ & $\begin{array}{l}\text { Age } \\
\text { (year) }\end{array}$ & $\begin{array}{l}\text { Male } \\
(\%)\end{array}$ & $\begin{array}{l}\text { Trial } \\
\text { population }\end{array}$ & $\begin{array}{l}\text { Adverse } \\
\text { events } \\
(\%)\end{array}$ \\
\hline $\begin{array}{l}\text { Aliasgharzadeh } \\
\text { (2015) [10] }\end{array}$ & Iran & D & $\begin{array}{l}\text { RD } 5 \text { g with a cup of } \\
\text { water during a meal } \\
\text { twice daily (30), or } \\
\text { maltodextrin with a } \\
\text { cup of water (25) }\end{array}$ & 8 & OADs & 5 & $\begin{array}{l}\text { RD: } 31.8 \\
\text { Control: } \\
30.8\end{array}$ & $\begin{array}{l}\text { RD: } 7.8 \\
\text { Control: } \\
8.2\end{array}$ & $\begin{array}{l}\text { RD: } 49.2 \\
\text { Control: } \\
49.6\end{array}$ & 0 & $\begin{array}{l}\text { T2DM } \\
\mathrm{BMI}>25\end{array}$ & None \\
\hline $\begin{array}{l}\text { Guerin (2013) } \\
{[16,17]}\end{array}$ & China & $\mathrm{D}$ & $\begin{array}{l}250 \mathrm{ml} \text { of orange } \\
\text { juice containing RD } 4 \\
\mathrm{~g}(20), \mathrm{RD} 7 \mathrm{~g}(20), \\
\text { RD } 9 \mathrm{~g}(20) \text {, or RD } 12 \\
\mathrm{~g} \text { twice daily (20), or } \\
250 \mathrm{ml} \text { of orange } \\
\text { juice only (20) }\end{array}$ & 9 & None & 4 & $\begin{array}{l}\text { RD: } 26.0 \\
\text { Control: } \\
26.0\end{array}$ & N. R. & $\begin{array}{l}\text { RD: } 44.7 \\
\text { Control: } \\
45.0\end{array}$ & 50 & BMI 24-28 & None \\
\hline $\begin{array}{l}\mathrm{Li}(2010) \\
{[18,19]}\end{array}$ & China & D & $\begin{array}{l}250 \mathrm{ml} \text { of fruit juice } \\
\text { containing } 17 \mathrm{~g} \mathrm{RD} \\
\text { twice daily (57), or } \\
250 \mathrm{ml} \text { of fruit juice } \\
\text { containing } \\
\text { maltodextrin (56) }\end{array}$ & 12 & None & 5 & $\begin{array}{l}\text { RD: } 24.5 \\
\text { Control: } \\
24.5\end{array}$ & $\begin{array}{l}\text { RD: } 5.8 \\
\text { Control: } \\
5.8\end{array}$ & $\begin{array}{l}\text { RD: } 30.4 \\
\text { Control: } \\
31.6\end{array}$ & 100 & BMI 24-28 & None \\
\hline
\end{tabular}

$R C T$ randomized controlled trial, $D$ double masked, $R D$ resistant dextrin, $N$. $R$. not reported, OADs oral antidiabetic drugs, $B M I$ body mass index, $H b A 1 c$ Hemoglobin A1c, T2DM type 2 diabetes mellitus
Additional records identified through other sources $(\mathrm{n}=1)$

Records excluded

$$
(\mathrm{n}=399)
$$

Full text studies excluded

with reasons $(n=35)$ :

Not an RCT (1)

Cross-over study (13)

Not evaluating RD (7)

Not all overweight or obese (8)

Including other interventions (1)

High vs. low dose response trial (1)

Not reporting BMI (3)

Low quality RCT (1) 
in the meta-analysis. Two trials conducted by Guerin et al. $[16,17]$ were the same RCT (Guerin 2013) with multiple reports, except for adverse events. Similarly, the trials conducted by Li et al. [18] and Guerin et al. [19] were the same RCT (Li 2010) with different main outcomes (i.e., BMI and body weight). All trials were randomized, placebo-controlled, double-masked studies. The sample sizes of the RCTs ranged between 55 and 113 subjects. The doses of RD ranged between 10 and $34 \mathrm{mg} /$ day. The durations of RCTs ranged between 8 and 12 weeks. Only one trial enrolled participants with type 2 diabetes [10]. All RCTs were conducted in Asian countries such as Iran and China. All trials were published in English.

\section{Quality assessment}

All RCTs were assessed as high quality (Table 1). One RCT that scored 4 points provided no information on participant withdrawal $[16,17]$. We also assessed the risk of bias of RCTs based on the Cochrane handbook [13]. Three trials had a low risk of bias for all seven domains $[10,16-19]$.

\section{Meta-analysis of a comparison of weight loss between RD and the control}

Three trials were included in the meta-analysis of a comparison of BMI between RD and the control [10, 16-19]. Statistical heterogeneity was observed among trials $\left(\mathrm{I}^{2}=\right.$ $78 \%)$. RD significantly decreased BMI in overweight adults [mean difference -0.39 (95\% CI -0.57 to -0.21$) \mathrm{kg} / \mathrm{m}^{2}$, $p<0.01]$. The subgroup analysis by follow-up at $8-9$ weeks and 12-13 weeks showed a significant result [mean difference $-0.30(95 \% \mathrm{CI}-0.33$ to -0.27$) \mathrm{kg} / \mathrm{m}^{2}$, $p<0.01$; mean difference -0.50 (95\% CI -0.63 to -0.21 ) $\mathrm{kg} / \mathrm{m}^{2}, p<0.01$ ] (Fig. 2).

Three trials $[10,16-19]$ were included in the metaanalysis of a comparison of body weight between RD and the control. No statistical heterogeneity was observed across trials $\left(\mathrm{I}^{2}=0 \%\right)$. RD significantly reduced body weight in overweight adults [mean difference -0.81 (95\% CI -0.93 to -0.69$) \mathrm{kg}, p<0.01$ ]. The subgroup analysis by follow-up at 8-9 weeks and 12-13 weeks showed a significant result [mean difference $-0.80(95 \%$ CI -0.92 to -0.68$) \mathrm{kg}, p<0.01$; mean difference -1.60 (95\% CI -2.80 to -0.40$) \mathrm{kg}, p<0.01$ ] (Fig. 3).

\section{Adverse events}

None of the RCTs examined reported any adverse events (Table 1).

\section{Additional analyses}

The subgroup analysis excluding patients with type 2 diabetes [10] showed that the effects of RD on BMI and body weight remained unchanged (Table 2). Another subgroup analysis including subjects with a BMI of 25 or more showed no significant results in BMI or body weight. Another subgroup analysis excluding the RCT with the largest sample size (Li 2010) showed significant results in BMI and body weight $[18,19]$ (Table 2). The results of the sensitivity analysis using a fixed-effects model were similar to those obtained using a randomeffects model (Table 2).

\section{Discussion}

To the best of our knowledge, we are the first to conduct a systematic review with a meta-analysis in order to assess the effects of RD for weight loss with those of a placebo in overweight adults. Our review suggests that RD exerts beneficial effects on BMI and body weight in overweight adults.

With a focus on each individual RCT, it is noteworthy that the studies by $\mathrm{Li}$ in $2010[18,19]$ had the lowest mean BMI at baseline $\left(24.5 \mathrm{~kg} / \mathrm{m}^{2}\right)$ and the highest daily dose of RD (34 g/day) in our review. Additionally, the

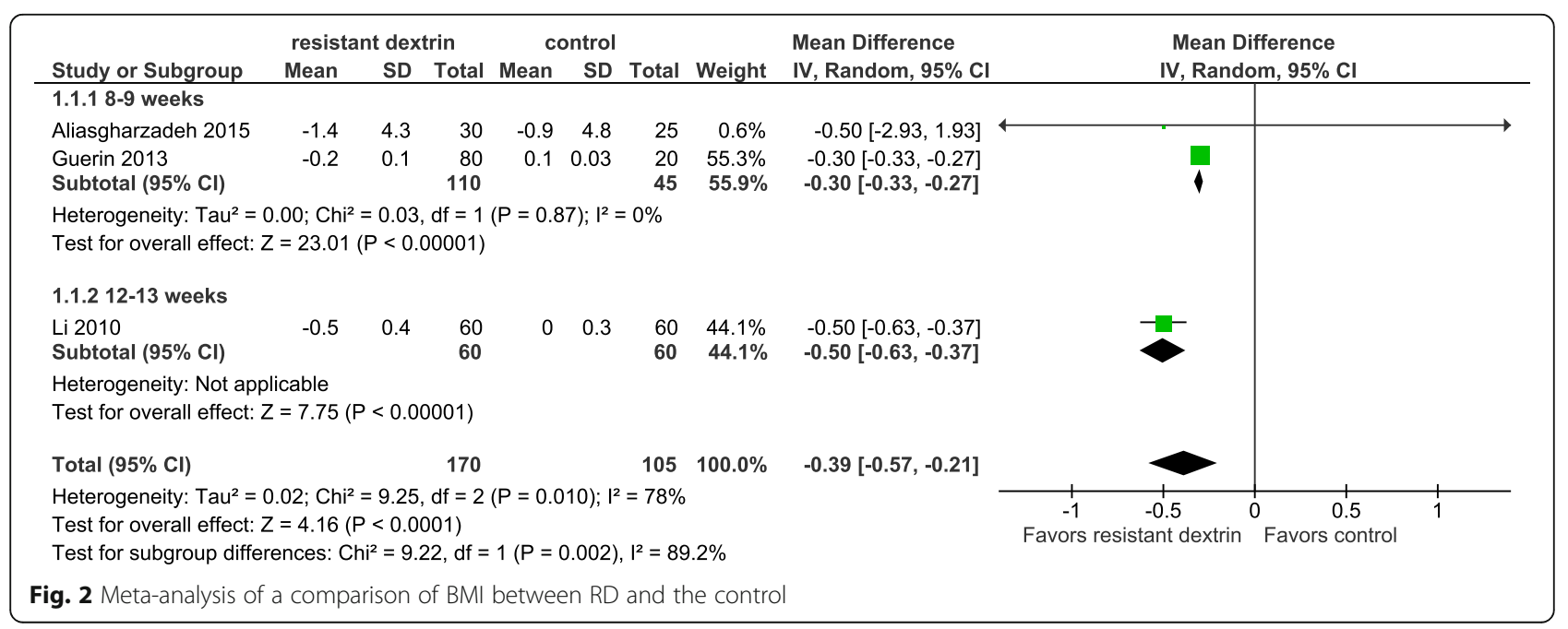




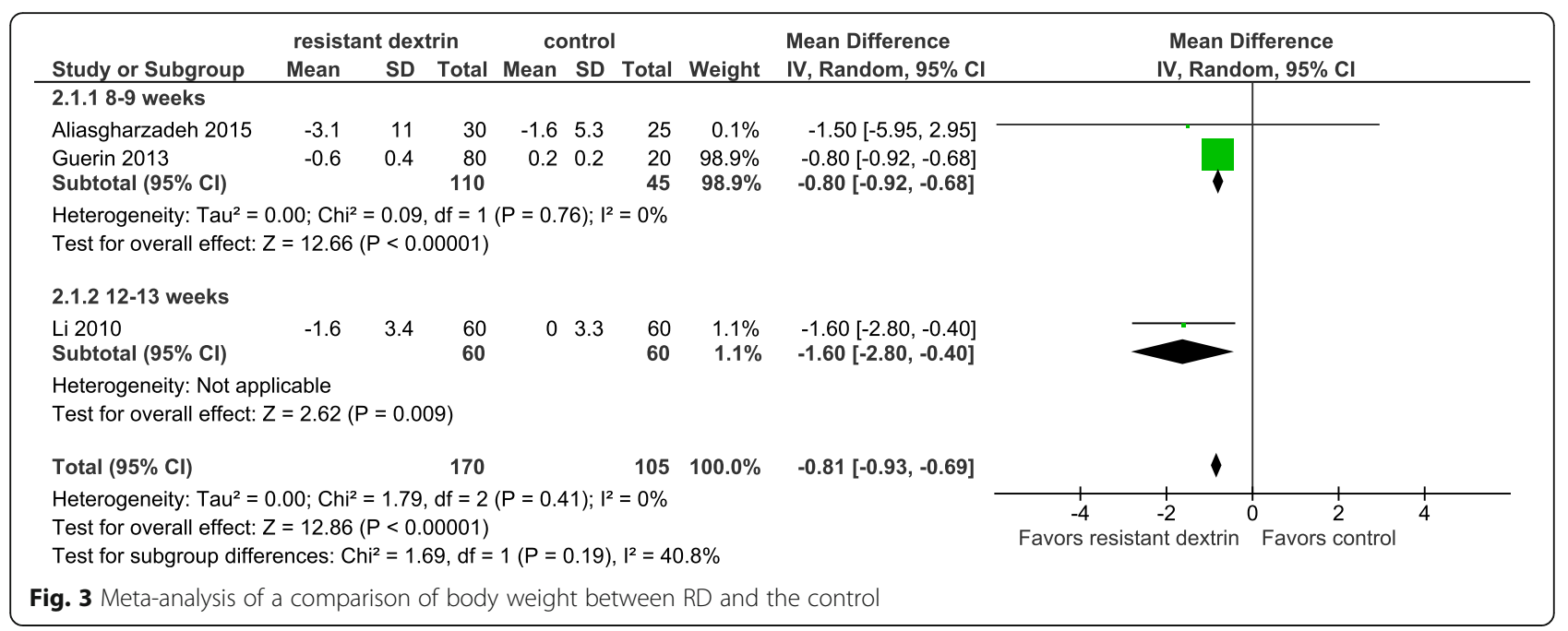

RCT showed the greatest mean differences in BMI and body weight, which were significant [mean difference $-0.5(95 \% \mathrm{CI}-0.6$ to -0.4$) \mathrm{kg} / \mathrm{m}^{2}$, mean difference -1.6 $(95 \% \mathrm{CI}-2.8$ to -0.4$) \mathrm{kg} / \mathrm{m}^{2}$, respectively]. In contrast, another study did not obtain significant findings in any case [10]. The trial by Aliasgharzadeh et al. [10] also had the greatest mean difference in BMI, but this was not significant [mean difference -0.5 ( $95 \%$ CI -2.9 to 1.9) $\mathrm{kg} / \mathrm{m}^{2}$; however, patients in that trial [10] took glibenclamide, which has been suggested to affect weight gain [21].

As expected, when we excluded the RCT with the largest sample size (Li 2010) $[18,19]$, the effects of BMI and body weight remained significant between RD and the control. In other analyses, excluding the trial by Aliasgharzadeh et al. [10], which used oral antidiabetic drugs in type 2 diabetic patients, significant differences were observed in the combined results of BMI and body weight. We speculated that the trial with the greatest weight (Guerin 2013) [16, 17] given by the smallest standard deviation may contribute to these significant results.

The Food and Drug Administration assessment indicated that the proportion of patients who achieved clinically meaningful weight loss of $5 \%$ at one year by using an anti-obesity drug was $50 \%$ or less [22, 23]. Another RCT showed that the initial weight loss response at 12 weeks predicted weight loss after one year [24]. If RD achieves an initial body weight loss of $5 \%$ at least at one year, it may be of clinical value for weight loss. However, our review only included 3 RCTs with a duration of 12 weeks or shorter. Therefore, a larger number of RCTs with a longer duration are needed in order to evaluate the efficacy of RD.

Our results showed that BMI was significantly lower with RD than with the control. However, all RCTs pooled in our review were conducted in Asian countries. Additionally, two RCTs included Chinese participants who had a lower mean BMI of 30 or less (Table 1). Collectively, this means that RD may only improve BMI in

Table 2 Results of sub-analyses

\begin{tabular}{|c|c|c|c|c|c|c|c|}
\hline & Outcome & Trial, $n$ & $\mathrm{RD}, n$ & Control, $n$ & $\begin{array}{l}\text { Mean Difference } \\
{[95 \% \mathrm{Cl}]}\end{array}$ & Heterogeneity (\%) & $\begin{array}{l}\text { Test for the overall effect } \\
(P \text { value })\end{array}$ \\
\hline \multirow[t]{2}{*}{ Excluding patients with type 2 diabetes } & $\begin{array}{l}\mathrm{BMl} \\
\left(\mathrm{kg} / \mathrm{m}^{2}\right)\end{array}$ & 2 & 140 & 80 & $-0.38[-0.60,-0.15]$ & 92 & 0.001 \\
\hline & BW (kg) & 2 & 140 & 80 & $-0.97[-1.61,-0.33]$ & 41 & 0.003 \\
\hline \multirow[t]{2}{*}{ Including subjects with a BMI > 25} & $\begin{array}{l}\mathrm{BMl} \\
\left(\mathrm{kg} / \mathrm{m}^{2}\right)\end{array}$ & 1 & 30 & 25 & $-0.50[-2.93,1.93]$ & N. A. & 0.69 \\
\hline & BW (kg) & 1 & 30 & 25 & $-1.50[-5.95,2.95]$ & N. A. & 0.51 \\
\hline \multirow[t]{2}{*}{$\begin{array}{l}\text { Excluding the RCT with the largest } \\
\text { sample size (Li 2010) }\end{array}$} & $\begin{array}{l}\mathrm{BMl} \\
\left(\mathrm{kg} / \mathrm{m}^{2}\right)\end{array}$ & 2 & 110 & 45 & $-0.30[-0.33,-0.27]$ & 0 & $<0.001$ \\
\hline & BW (kg) & 2 & 110 & 45 & $-0.80[-0.92,-0.68]$ & 0 & $<0.001$ \\
\hline \multirow[t]{2}{*}{$\begin{array}{l}\text { Sensitivity analysis using the fixed-effect } \\
\text { model }\end{array}$} & $\begin{array}{l}\mathrm{BMl} \\
\left(\mathrm{kg} / \mathrm{m}^{2}\right)\end{array}$ & 3 & 170 & 105 & $-0.31[-0.33,-0.28]$ & 78 & $<0.001$ \\
\hline & BW (kg) & 3 & 170 & 105 & $-0.81[-0.93,-0.69]$ & 0 & $<0.001$ \\
\hline
\end{tabular}


East-Asians with a BMI of 30 or less. A narrative review showed that BMI was lower in Asians than in Non-Asians such Europeans. For example, the prevalence of obesity with a BMI of 30 or more is approximately seven-fold higher among Europeans than Chinese [2]. Therefore, the efficacy of RD for weight loss in Non-Asians or Asians with a BMI of 30 or more remains unclear.

A recent meta-analysis revealed that dietary fiber such as RD significantly increased self-reported feelings of satiety in healthy adults [25]. Aliasgharzadeh et al. [10] hypothesized that RD may enhance satiety by stimulating the secretion of gut hormones such as glucagon-like peptide-1, similar to other dietary fibers [26]. Furthermore, an epidemiological study demonstrated that fat correlated with increases in endotoxin [27]. These mechanisms appear to be involved in RD-induced reductions in BMI and body weight.

Our review has some limitations. There may be publication biases because this review only included published RCTs. In addition, we did not analyze the publication bias because the number of RCTs that we were able to collect was too small $(n=3)$ to test the funnel plot. Therefore, the present results may be affected if unpublished findings become available. The combined results need to be interpreted with caution because there was significant heterogeneity in at least one outcome. The small number of RCTs in our review may cause this heterogeneity.

\section{Conclusion}

Based on the limited evidence available, our review suggests that RD exerts beneficial effects on BMI and body weight in overweight adults. However, our results represent considerable heterogeneity and the trials pooled in our review have shorter follow-ups or limited populations. Thus, more RCTs with different populations, or longer follow-ups are needed in order to confirm that supplementation with RD has beneficial effects for weight loss in overweight adults. We consider this review to provide important information for the future submission of food with health claims.

\section{Abbreviations}

BMI: Body mass index; Cl: Confidence interval; RCT: Randomized controlled trial; RD: Resistant dextrin

\section{Acknowledgment}

I would like to thank Yuki Tobita for the useful discussions.

\section{Funding}

None.

\section{Availability of data and materials}

The datasets used and/or analyzed during the present study are available from the corresponding author on reasonable request.

\section{Authors' contributions}

JM conceived and designed the study. JM, MY performed the systematic review of literature. JM, YT analyzed and interpreted the data. JM wrote the manuscript. All authors read and approved the final manuscript.

\section{Competing interests}

The authors declare that they have no competing interests.

Consent for publication

Not applicable.

Ethics approval and consent to participate

Not applicable.

\section{Publisher's Note}

Springer Nature remains neutral with regard to jurisdictional claims in published maps and institutional affiliations.

\section{Author details}

${ }^{1}$ Laboratory of Clinical Pharmacy Education, School of Pharmacy, Kitasato University, 5-9-1, Shirokane, Minato-ku, Tokyo 108-8641, Japan. ${ }^{2}$ Laboratory of Pharmacy Practice and Science I, 1-15-1, Kitasato, Minami-Ku, Sagamihara, Kanagawa 252-0375, Japan. ${ }^{3}$ Department of Pharmacy, Kitasato University Medical Center, 6-100 Arai, Kitamoto-shi, Saitama 364-8501, Japan.

${ }^{4}$ Department of Pharmacy, Kitasato University Hospital, 1-15-1, Kitasato, Minami-Ku, Sagamihara, Kanagawa 252-0375, Japan.

Received: 9 February 2017 Accepted: 10 May 2017

Published online: 16 May 2017

\section{References}

1. World Health Organization. Obesity and overweight. Fact sheet [updated June 2016]. http://www.who.int/mediacentre/factsheets/fs311/en/. Accessed 27 Dec 2016.

2. Yoon $\mathrm{KH}$, Lee JH, Kim JW, Cho JH, Choi YH, Ko SH, Zimmet P, Son HY. Epidemic obesity and type 2 diabetes in Asia. Lancet. 2006;368:1681-8.

3. Odegaard AO, Koh WP, Vazquez G, Arakawa K, Lee HP, Yu MC, Pereira MA. BMI and diabetes risk in Singaporean Chinese. Diabetes Care. 2009;32:1104-6.

4. Chandalia M, Garg A, Lutjohann D, von Bergmann K, Grundy SM, Brinkley LJ. Beneficial effects of high dietary fiber intake in patients with type 2 diabetes mellitus. N Engl J Med. 2000;342:1392-8.

5. Ludwig DS, Pereira MA, Kroenke CH, Hilner JE, Van Horn L, Slattery ML, Jacobs Jr DR. Dietary fiber, weight gain, and cardiovascular disease risk factors in young adults. JAMA. 1999;282:1539-46.

6. Lyon MR, Reichert RG. The effect of a novel viscous polysaccharide along with lifestyle changes on short-term weight loss and associated risk factors in overweight and obese adults: an observational retrospective clinical program analysis. Altern Med Rev. 2010;15:68-75.

7. Slavin $J$, Savarino V, Paredes-Diaz A, Fotopoulos G. A review of the role of soluble fiber in health with specific reference to wheat dextrin. J Int Med Res. 2009:37:1-17.

8. Lefranc-Millot C. NUTRIOSE ${ }^{\circledast}$ 06: a useful soluble dietary fibre for added nutritional value. Nutrition Bulletin. 2008;33:234-9.

9. Yamamoto T, Yamamoto K, Fukuhara Y, Fukui T, Kishimoto Y, Okuma K, Matsuoka Y, Isozaki K, Nagao K, Yamamoto T, Tokunaga K. Effect of indigestible dextrin on visceral fat accumulation. J Jpn Soc Study Obes. 2007;13:34-41 (In Japanese).

10. Aliasgharzadeh A, Dehghan P, Gargari BP, Asghari-Jafarabadi M. Resistant dextrin, as a prebiotic, improves insulin resistance and inflammation in women with type 2 diabetes: a randomised controlled clinical trial. $\mathrm{Br}$ J Nutr. 2015;113:321-30.

11. Livesey $\mathrm{G}$, Tagami $\mathrm{H}$. Interventions to lower the glycemic response to carbohydrate foods with a low-viscosity fiber (resistant dextrin): metaanalysis of randomized controlled trials. Am J Clin Nutr. 2009;89:114-25.

12. Jadad AR, Moore RA, Carroll D, Jenkinson C, Reynolds DJ, Gavaghan DJ, McQuay HJ. Assessing the quality of reports of randomized clinical trials: is blinding necessary? Control Clin Trials. 1996;17:1-12

13. Higgins JPT, Green S (eds). Cochrane Handbook for Systematic Reviews of Interventions, Version 5.1.0 [updated March 2011]: The Cochrane Collaboration; 2011. http://handbook.cochrane.org/. Accessed 27 Dec 2016.

14. DerSimonian R, Laird N. Meta-analysis in clinical trials. Control Clin Trials. 1986;7:177-88.

15. Follmann D, Elliott $P$, Suh I, Cutler J. Variance imputation for overviews of clinical trials with continuous response. J Clin Epidemiol. 1992;45:769-73. 
16. Guérin-Deremaux L, Pochat M, Reifer C, Wils D, Cho S, Miller LE. The soluble fiber NUTRIOSE induces a dose-dependent beneficial impact on satiety over time in humans. Nutr Res. 2011;31:665-72.

17. Guérin-Deremaux L, Pochat M, Reifer C, Wils D, Cho S, Miller LE. Dose-response impact of a soluble fiber, NUTRIOSE ${ }^{\oplus}$, on energy intake, body weight and body fat in humans. Global Epidemic Obesity. 2013;1:2.

18. Li S, Guerin-Deremaux L, Pochat M, Wils D, Reifer C, Miller LE. NUTRIOSE dietary fiber supplementation improves insulin resistance and determinants of metabolic syndrome in overweight men: a double-blind, randomized, placebo-controlled study. Appl Physiol Nutr Metab. 2010;35:773-82.

19. Guerin-Deremaux L, Li S, Pochat M, Wils D, Mubasher M, Reifer C, Miller LE. Effects of NUTRIOSE ${ }^{\oplus}$ dietary fiber supplementation on body weight, body composition, energy intake, and hunger in overweight men. Int J Food Sci Nutr. 2011;62:628-35.

20. Moher D, Liberati A, Tetzlaff J, Altman DG, PRISMA Group. Preferred reporting items for systematic reviews and meta-analyses: the PRISMA statement. Ann Intern Med. 2009:151:264-9.

21. Seino Y, Rasmussen MF, Nishida T, Kaku K. Efficacy and safety of the once-daily human GLP-1 analogue, liraglutide, vs glibenclamide monotherapy in Japanese patients with type 2 diabetes. Curr Med Res Opin. 2010;26:1013-22.

22. Knowler WC, Barrett-Connor E, Fowler SE, Hamman RF, Lachin JM, Walker EA, Nathan DM. Diabetes Prevention Program Research Group. Reduction in the incidence of type 2 diabetes with lifestyle intervention or metformin. $N$ Engl J Med. 2002;346:393-403.

23. Colman E, Golden J, Roberts M, Egan A, Weaver J, Rosebraugh C. The FDA's assessment of two drugs for chronic weight management. N Engl J Med. 2012;367:1577-79.

24. Finer N, Ryan DH, Renz CL, Hewkin AC. Prediction of response to sibutramine therapy in obese non-diabetic and diabetic patients. Diabetes Obes Metab. 2006;8:206-13.

25. Kellow NJ, Coughlan MT, Reid CM. Metabolic benefits of dietary prebiotics in human subjects: a systematic review of randomised controlled trials. Br J Nutr. 2014:111:1147-61.

26. Cani PD, Lecourt E, Dewulf EM, Sohet FM, Pachikian BD, Naslain D, De Backer F, Neyrinck AM, Delzenne NM. Gut microbiota fermentation of prebiotics increases satietogenic and incretin gut peptide production with consequences for appetite sensation and glucose response after a meal. Am J Clin Nutr. 2009:90:1236-43.

27. Amar J, Burcelin R, Ruidavets JB, Cani PD, Fauvel J, Alessi MC, Chamontin B, Ferriéres J. Energy intake is associated with endotoxemia in apparently healthy men. Am J Clin Nutr. 2008;87:1219-23.

\section{Submit your next manuscript to BioMed Central and we will help you at every step:}

- We accept pre-submission inquiries

- Our selector tool helps you to find the most relevant journal

- We provide round the clock customer support

- Convenient online submission

- Thorough peer review

- Inclusion in PubMed and all major indexing services

- Maximum visibility for your research

Submit your manuscript at www.biomedcentral.com/submit

C Biomed Central 